\title{
The experience of international postgraduate students on a distance-learning programme
}

DOI:

10.1080/01587919.2018.1520038

10.9743/jeo.2017.14.2.3

\section{Document Version}

Accepted author manuscript

Link to publication record in Manchester Research Explorer

\section{Citation for published version (APA):}

Harrison, R. A., Harrison, A., Robinson, C., \& Rawlings, B. (2018). The experience of international postgraduate students on a distance-learning programme. Distance Education, 39(4), 480-494.

https://doi.org/10.1080/01587919.2018.1520038, https://doi.org/10.9743/jeo.2017.14.2.3

\section{Published in:}

Distance Education

\section{Citing this paper}

Please note that where the full-text provided on Manchester Research Explorer is the Author Accepted Manuscript or Proof version this may differ from the final Published version. If citing, it is advised that you check and use the publisher's definitive version.

\section{General rights}

Copyright and moral rights for the publications made accessible in the Research Explorer are retained by the authors and/or other copyright owners and it is a condition of accessing publications that users recognise and abide by the legal requirements associated with these rights.

\section{Takedown policy}

If you believe that this document breaches copyright please refer to the University of Manchester's Takedown Procedures [http://man.ac.uk/04Y6Bo] or contact uml.scholarlycommunications@manchester.ac.uk providing relevant details, so we can investigate your claim.

\section{OPEN ACCESS}




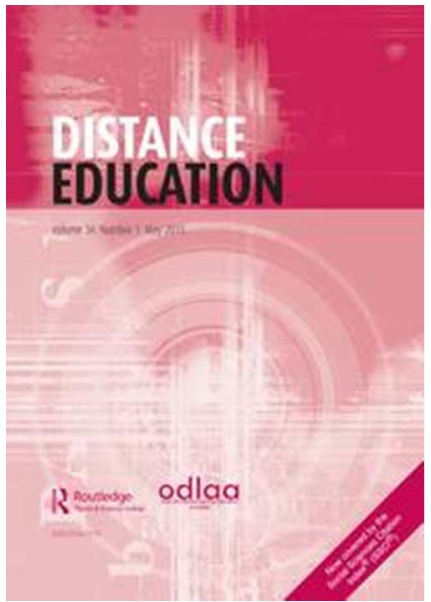

\section{The experience of international postgraduate students on a distance-learning programme}

\begin{tabular}{|r|l|}
\hline Journal: & Distance Education \\
\hline Manuscript ID & CDIE-2017-0123.R2 \\
\hline Manuscript Type: & Original Research \\
\hline Keywords: & $\begin{array}{l}\text { transnational, curriculum design, distance learning, internationalization, } \\
\text { online }\end{array}$ \\
\hline Abstract: & $\begin{array}{l}\text { Online distance-learning (ODL) programmes in higher education enable } \\
\text { students to remain in their domicile country to study with institutions } \\
\text { based in other countries. ODL students can find themselves studying with } \\
\text { others from many different countries, adding greater heterogeneity of } \\
\text { personal, environmental and cultural perspectives compared with on- } \\
\text { campus education. This is likely to impact the learners' experience in } \\
\text { different ways. The current research examined the experience of students } \\
\text { living outside of the European Union, who were registered with an ODL } \\
\text { programme with a higher education institution based in the European } \\
\text { Union. The research identified a number of important factors that } \\
\text { influenced the students' experience in different ways. The results } \\
\text { emphasize the need for ODL programmes to fully consider individual } \\
\text { students' contexts, regardless of where they are in the world, and for these } \\
\text { needing to be embedded in a pedagogical framework that gives due } \\
\text { consideration to globally diverse cohorts of students }\end{array}$ \\
\hline \hline
\end{tabular}




\section{Author contact details}

Dr Roger Harrison

Senior Lecturer in Public Health

School of Health Sciences

Division of Population Health, Health Services Research and Primary Care

The University of Manchester

Room C4.6 Ellen Wilkinson Building

Oxford Road

Manchester M13 9PT

England.

Email: roger.harrison@manchester.ac.uk

Annie Harrison

Lecturer in Public Health

School of Health Sciences

Division of Population Health, Health Services Research and Primary Care

The University of Manchester

Room C4.6 Ellen Wilkinson Building

Oxford Road

Manchester M13 9PT

England.

Email: Annie.harrison@manchester.ac.uk

Christine Robinson

Lecturer in Public Health

School of Health Sciences

Division of Population Health, Health Services Research and Primary Care

The University of Manchester

Room C4.6 Ellen Wilkinson Building

Oxford Road

Manchester M13 9PT

England.

Email: Christine.A.Robinson@manchester.ac.uk

Barbara Rawlings

Senior Research Consultant

c/o Room C4.6 Ellen Wilkinson Building

Oxford Road

Manchester M13 9PT

England.

Email: Barbara.Rawlings@Talk21.com 


\title{
The experience of international postgraduate students on a distance-learning programme
}

\author{
Roger A Harrison ${ }^{a}{ }^{\bullet}$, Annie Harrison ${ }^{\mathrm{b}}$, Christine Robinson ${ }^{\mathrm{c}}$, and Barbara \\ Rawlings ${ }^{\mathrm{d}}$ \\ ${ }^{a, b, c}$ Division of Population Health, Health Services Research and Primary Care, \\ The University of Manchester, Manchester, England; ${ }^{d}$ Senior research consultant \\ (Received $<$ October 26, 2017>; final version received $<$ July 30, 2018>)
}

\begin{abstract}
Online distance-learning (ODL) programmes in higher education enable students to remain in their domicile country to study with institutions based in other countries. ODL students can find themselves studying with others from many different countries, adding greater heterogeneity of personal, environmental and cultural perspectives compared with oncampus education. This is likely to impact the learners' experience in different ways. The current research examined the experience of students living outside of the European Union, who were registered with an ODL programme with a higher education institution based in the European Union. The research identified a number of important factors that influenced the students' experience in different ways. The results emphasize the need for ODL programmes to fully consider individual students' contexts, regardless of where they are in the world, and for these needing to be embedded in a pedagogical framework that gives due consideration to globally diverse cohorts of students.
\end{abstract}

Keywords: transnational; curriculum design; distance learning; internationalization; online

\section{Background}

The Internet is omnipresent in many parts of the world and people's recreational, work and study environments. It is estimated that almost half the world's population, around 3.4 billion people, have access to the internet from home (Internet Live Stats, 2016), and earlier predictions of almost individual global

\footnotetext{
• Corresponding author. Email: roger.harrison@manchester.ac.uk
} 
connectivity seem a realistic proposition (Goldhill, 2013). In the past few years, the affordances following the introduction of Web 2.0 have produced a second wave of transformation, capable of enabling more participatory and collaborative online opportunities (Mechant, 2014).

In the field of education, the Internet has undoubtedly made possible formal and informal online learning for millions of children and adult learners around the world (Altbach, Reisberg, \& Rumbley, 2010; Bates, 2015), along with creating unprecedented variety in what people learn and how (British Council, 2013; Knight, 2016). In theory, students and educational providers are unbounded by location (Kosmützky \& Putty, 2016). Thus, millions of students are studying online with an educational provider in a different country, without having to cross jurisdictional borders.

Of relevance to the current study is the agreement of the 28 member states of the European Union (EU) (which at the time of writing still includes the United Kingdom) to charge the same tuition fees for national and non-national (i.e., international) students and to give them equality of access (Katsarova, 2015). As a consequence, the UK and other EU higher education institutes (HEIs) have since been able to make significant increases to their admission fees for international students, making these students far more profitable than students whose domiciliary country is within the limits of the EU. Thus, HEIs have been keen to expand and promote online distance-learning (ODL) programmes to recruit international students. Similarly, international students have been attracted to ODL as it negates visa requirements and travel, leaving many aspects of their day-to-day environment untouched. 
However, the extent that HEIs can provide high-quality online education, to students in other countries, often with environments quite different to their own, has not been adequately researched. A particular concern is the ability of programmes and academics to sufficiently contextualise the learning materials for students who can be living in disparate parts of the world (Collinson \& Halliwell, 2014; Rasi, Hautakangas, \& Väyrynen, 2014). Moreover, the impact of this on students' learning experience is far from clear.

The aim of the current research was to gain a deeper understanding of the learning experience of international students (non-EU students), registered on an ODL programme. The study is part of a wider programme of work that seeks to address a persistent and pervasive divide in learning attainment in higher education for EU students when compared with non-EU students (LSE Students' Union, 2016). The qualitative study aimed to capture more of the richness of students' experiences rather than making comparisons across students from different countries.

\section{Methods}

This qualitative investigation recruited students from an online Master in Public Health (MPH) programme at the University of Manchester, UK. This is an established ODL programme that recruits students from all over the world. The students usually come from a diverse professional and social background, have a mean age of around 35 years, and three-quarters of the annual intake are women. The programme aims to meet the variety of educational needs by providing a wide range of optional and mandatory units and flexible models for the dissertation. The key entry requirements include a relevant undergraduate degree 
(or equivalent). Students from countries where English is not their primary language need to demonstrate English-language proficiency equivalent to level 6.5 from the International English Language Testing System (IELTS, 2018).

\section{Data collection}

Data were collected using semi-structured interviews with individual students carried out by telephone or Skype. The interviews were intended to last up to 60 minutes. The themes for the interview schedule were based on a review of the published evidence relating to online learners, international students in higher education and gaps in attainment. We sought opportunistic feedback on the study methods and the interview schedule from academics with experience of teaching on the programme (23 in number) and made minor modifications before proceeding. The final themes for exploration in the interviews were reasons for taking the online programme; expectations and experience; issues arising in terms of cultural dissonance between the UK-based programme and the student's own country; their experience of studying with students around the world. Interviewers asked an initial set of basic questions, and then probed further whenever they felt respondents had more to say, allowing respondents to talk at length. Thus, as far as possible, interviewees' own words were captured.

\section{Sample size}

The sample was dictated by the circumstances of the ODL programme, along with the willingness and ability for non-EU students to take part in online or telephone interviews. Qualitative research is more about developing themes and ideas and not about knowing at the start how many should be in a sample 
(Hammersley \& Atkinson, 2007). Consequently, the size of the sample was dictated by the availability or interest of students. Thus, if this turned out to be smaller than had been hoped, it would still offer rich information for this underresearched subject and provide additional insight into the learning needs of a range of international distance-learning students. Moreover, it is widely argued that the notion of saturation provides little help in designing a study. For example, in a study of 60 women, saturation occurred after 12 had been interviewed (Guest, MacQueen, \& Namey, 2012), and in three studies, saturation of ideas occurred for between 14 and 17 respondents (Francis et al., 2010).

\section{Recruitment}

To be eligible for the study, students needed to be currently enrolled on the online MPH (part-time or full-time), and have been born, and remained living, outside of the EU at the time of study (i.e., what some would refer to as non-national, or borderless students, studying at a distance by online learning).

\section{Ethics}

Approval from the university's Research Ethics Committee was obtained before proceeding with any interviews. All international students registered on the MPH were emailed an invitation to participate, and which included the formal participant information sheet giving a written explanation of the purpose, process and format of the study and instructions for returning written, signed consent if they wished to participate. To maintain subject confidentiality, the interviews and analysis were carried out by researchers external to the programme, and which aimed to reduce the potential for bias. Furthermore, it was not possible to report 
which specific country a participant was from because it could have reduced the ability to ensure anonymity. For ease of reading, all students have been referred to using the female pronoun (i.e., her/she).

\section{Analysis}

Interviews were recorded and later transcribed for analysis. A form of thematic analysis was employed to allow the topics chosen by the respondents to be identified and examined (Braun \& Clarke, 2006). This approach offers a particular structure to grounded theory (Glaser, 1992; Strauss \& Corbin, 1998) and recommends a series of stages. By working through these stages, researchers can have confidence that the story they tell is essentially authentic, and that things have not been overlooked. The 6-phase analytic method (Braun \& Clarke, 2006) is intended to help, not to limit research practice. Thus, recommended approaches to analysis include pencil and paper methods with visual representation, mind maps and the organising of themes into piles (Braun \& Clarke, 2006). This reflects similar methods that utilise computer software such as Excel and NVivo to manage and analyse data (Nowell, Norris, White, \& Moules, 2017).

In the current study, the method consisted primarily of listening to the recordings, reading the transcripts, and slowly sorting respondents' diverse answers into a coherent framework that would make sense to a reader and would at the same time be rooted in the words and meanings of the students. This procedure of attending, sifting and writing is closest to the ethnographic methods of qualitative sociological researchers (Hammersley, 2015) and provides 
evidence through attention to detail. In practice, the framework was developed visually, by reading the transcripts over several times, cutting up copies with scissors, organising these fragments into piles and columns on a large table, resorting them and moving them round, noting when people seemed to be saying the same thing or when one person described a unique experience, and stapling them in categories to larger sheets of paper. This process was accompanied by several attempts to put the data into a coherent framework using mind mapping, and eventually coming up with a series of headings which seemed to capture and cover the range of answers and comments respondents had provided. On occasion the researcher went back to the research commissioner to check details about the course, but the data and the final results were entirely the product of the research and not influenced by course tutors or other professionals. Such people are knowledgeable but do not have what was wanted here - that is, the personal experience of being a student on this course.

\section{Results}

The qualitative interviews were carried out in 2014. During that time, there were 57 international students on the MPH programme and 27 (47\%) expressed an interest in the study. Of these, six were not available during the data collection period and 11 did not further respond. The final group of 10 students interviewed were eight women and two men, of whom four remained resident in their domicile high-income country and six in low and middle income countries, using economic data produced by the World Bank (2017) and based on that coincidental to the time of the students' interviews. The data have been grouped into a series of key themes arising from the exploratory thematic analysis. A code 
is used following any direct quotes to maintain anonymity of the student.

\title{
Overall experience of participating on the programme
}

Prior to enrolling on the course, students had anticipated that the content would comprise innovative theories and models, which were up-to-date, in current use, and that they would embrace and use new technology. That the course was led by a UK university seemed important too for some. For example, one student in a highly developed country said:

\begin{abstract}
I think that people are interested to see what the UK is doing and to learn from some of the stuff they've done. It seems like you guys will do it and ten years later we'll do the same thing. (TNE12:108-110)
\end{abstract}

The same student also said that she had checked before enrolling that the course would be recognised by her government and continued:

\footnotetext{
It would concern me if it wasn't you know, a well-rated, well-respected, visible university ... It was ranked recently higher than the university I went to. And, you know, it seemed respected and established, so that definitely played a role. (TNE12:521-5)
}

Students recognised that other students were enrolled from countries around the world and expected this to be reflected in the curriculum. There was an expectation that the course would enable the development of practical skills, to help go on to improve the population's health. One respondent, who had worked in public health for some time, anticipated that it would be interesting to hear 
how people did things in other countries and to learn from their experiences of running public health services and campaigns.

I'm a hands-on person and I was hoping to learn how to do things in a practical sense, like for example, how to make public health reports, how to interpret, to find evidence. (TNE06:88)

Students' experiences of the course varied widely and were both positive and negative. One student had expected that there would have been a greater use of the online learning environment and with it, more interaction with the teachers, more webinars and use of Skype. Instead, their experience was that most of the teaching relied on different sources of written content:

There's just a lot of new technology, so I guess I was expecting there'd be e-learning a bit more perhaps (TNE01:151-2).

A student in a low and middle income country, who had found the webinars very helpful, would have liked more of these:

I would have preferred a lot more webinars. A semester is usually ten weeks and we usually have one per course .... I would have loved like once a month. Because it helps you keep on your toes, you know when you're far from the rest and you interact with a computer. When you're in a low resource country, it's difficult. (TNE09:139-44 
Another felt that:

The social problems are the same ... And, you know, someone that's had to work on an e-cigarette file, maybe in God knows where, would be able to give something that I could probably take back to my work environment. (TNE01:400-3)

This student said that for her, the whole point of taking an international course was to be able to get some international discussion going, rather than take it at a local university with "me and a bunch of other government employees, or you know, doctors from the local hospital." (TNE01:415-7)

Others, however, found the communication initiated using Blackboard to be very helpful:

It's a good forum to exchange some ideas and yeah, we did exchange with other students and we have ended up making some friends through the Blackboard also, so that's good. (TNE06:101-9)

I think the Blackboard at the University of Manchester makes a big difference because somehow I felt part of the process of studying. I was able to engage with other students and some of the professors that are, who are pretty much present and support you. (TNE06:46-9).

We had a couple of programmes where we could interact as if we were in a virtual classroom. (TNE03:77-8). 
Some of the students interviewed had also felt inhibited or concerned about communicating with others on the course:

English is not my first language really and you are talking to people, writing to people you don't know and things like that, and you fear to be judged, and, you know, things like that. If you don't really get it right first time you end up holding back all the time. (TNE07:340-3)

One student felt that their cultural background led them to being concerned and reluctant to actually write their comments, which were available to other students and the tutor to read:

It's not in our culture, you know, like for those students from other countries, you know like the UK. They're used to write whatever they think, they ask, they write. (TNE05:278-280)

Instead of contributing directly to these discussions, she said she would look at what others had written. Sometimes others were asking the same questions that she wanted to ask, so she could benefit from those contributions:

I was used to sitting in a class and whenever I have a question, I have to ask the tutor, you see. But when it comes to go to the Blackboard, and ask by writing, sometimes you are not even sure if what you're asking is accurate, so you just end up you know, leaving it ... Sometimes I do hesitate. Is it really relevant to ask this question? Maybe it's stupid. It's a culture thing. (TNE05:285-95) 
Another said the discussion boards did not suit her. She would read what other people said, but not contribute:

I think I've been passive in the discussion boards, but with the webinars, I think I'm more comfortable. (TNE09:186-8)

One concern about electronic communication was voiced by a student who had had trouble with negative comments on her work given by a member of staff. She felt that had she been able to discuss the matter face-to-face, as she would on a conventional course, it would have been quickly resolved, and indeed may never have arisen in the first place:

The primary interaction I have with people is electronic and rather impersonal because they don't get to see me, and I don't get to see them, and perhaps they would have done things differently had they known me. (TNE12:301-3)

Several students mentioned that tutors had been helpful, and they felt supported:

I felt the support to students from the University programme was good. Most of the professors were quite responsive in terms of, if we asked questions they would respond not long after. (TNE06:103-5)

The level and quality of contact with tutors seems to have varied from module to module although it was mainly described as good: 
Some professors were responsive and others, it took them time, probably because they were too busy, or they had too many questions to answer. One of the courses which I enjoyed most, the professor was a bit missing in action. (TNE06:205-10)

This student felt the same problems would not have occurred in a face-to-face learning situation, where the tutors would have been more accessible. A student in a high-income country reported that there had been a lot of really good tutors on the programme, and said it was inevitable that some would not be so good:

It's going to be a mix, and I think you're going to get that at many institutions, not just Manchester. (TNE12:747-51)

A student reported that whilst she had fewer resources than many other places had, she did not feel the tutors were fully aware of this. She felt that tutors would be aware of the problems in the countries where more students come from, like Nigeria and Ghana, especially if each student mentions the same problem:

\footnotetext{
But ... I'm the only one from here, and it's an isolated place, so most of the tutors would not even know there's a student from this country on the course. (TNE03:314-318)
}

She continued: 
1

2

3

4

5

6

7

8

9

10

If it's just one student and you only have a problem once in a while sometimes you don't receive the same attention as students where there are four or five. (329-331)

Different expectations about the course were commented on in relation to its flexibility. One student said she thought she could take the training any time she liked, as she had done with a previous online course. But:

I've just come to realise that at the end of the week I have to post a discussion, so to make sure that I finish all my topics, you know. It's so scheduled which I didn't know, I didn't expect. I don't say it's bad, but people really don't realise that in fact online courses, it's very demanding. (TNE05:180-4).

Trying to incorporate the flexible approach to study, as part of a busy life in general hindered one student in contributing to the online discussions:

On Blackboard by the time I'd log on, I'd find that it was a long time past. People had given their responses and their comments, and the tutor had replied. I was kind of behind. (TNE15:227-9).

Studying along with students in different time zones created particular issues for any form or group task or assignment: 
Right now, you guys are five hours ahead of me, so there were times when I would have to wake up at like 3, 4 am just to be included in the group conversation. (TNE08:177-9)

She said that if she had the option she would prefer to keep away from group assessments because just coordinating is very difficult:

It's not impossible and if you have good teams and group meetings it's workable, but if you don't and that's always my worry. What if I don't get a good group? (184-6)

Another student had a suggestion for making it easier for students to work together despite the problems of time zones created by an international programme:

Maybe what could happen is the students put their time zone and where they live and maybe then the groups can organise based on that. Or if there's a file record of where each student is and their time zone, maybe when the lecturer does it, they use that as the basis. (TNR08:193-6)

Another student however found that the course to be as flexible as she expected:

One of the key things that drew me into this is the flexibility, you know, like I cannot look at something for a week and then work harder the following week, you know depending on what's going on in my life and at work. (TNE12:382-4). 
One student in a low-income country commented on how education is perceived by others in the local community:

So that's one of the challenges of having to be at home with young children. And you know our culture is different from the Western culture. If someone comes to pay you a visit and you say like you're studying, they won't understand. (TNE09:297-306)

\title{
Course content
}

Several of the students interviewed raised concerns about the relevance of the course materials to their own culture and community. This was more evident as students needed to focus or drill-down on a topic, and this disconnect between the course materials and their own circumstance had negative impacts:

\begin{abstract}
It makes you feel that you are alone in that place, you know. If you just see examples from some other place, some other place continuously you just lose touch. (TNE07:223-6).
\end{abstract}

In an effort to overcome this, the same student had tried to identify similarities between the course materials and their own circumstance:

We could just really like, see the difference between how we're doing and how my country is doing without feeling as if it was such a huge difference. Of course, it's a different country but you can see that it's related to us. (TNE07: 241-4). 
Yet trying to identify some of the different health systems, and how it all worked was confusing for one of the interviewees:

\begin{abstract}
I'm still not sure. Like I know it's all NHS, but you say they operate independently of one another, like that kind of thing, right? Like, how independent is each site from one another? (TNE12:569-572)
\end{abstract}

Some kind of overarching overview would be good to help us understand how it all plays into one another to begin with, that would be good. (TNE 12: 591-593)

Students seemed frustrated at the lack of relevant material, especially as they recognised its existence, but that many of the examples were UK based. At the same time, the diversity between the backgrounds and circumstances of actual students was a positive experience:

\begin{abstract}
Whenever I provide examples from my country it helps others, it helps the UK students and whenever they provide UK examples it helps me ... Whenever we have different case studies it's good, from India, from China, from UK, it's really good, good diversity. (224-230)
\end{abstract}

One student was very clear on how some of the material, like the case studies on Ebola and on a plague in Madagascar, was: 
Of zero relevance. (TNE01:194-5).

This conflicted with their expectations from attending a university in their own country, where they anticipated tutors would have understood and used local examples as part of the teaching. However, the student pointed out that this was not such a problem for them as they wanted to work in the UK anyway.

One student in a low and middle income country reported that the Health Economics module helped her to introduce systems of budgeting and prioritising which were new, and which enabled her organisation to think things through better before they began a project. Also, she had been asked to improve the quality of the public health facilities and found the topic on quality in the Management module particularly relevant to this. She found herself thinking about whether her organisation was approaching quality improvement the right way and was able to instigate useful changes:

\footnotetext{
You know ... it does not have to be a major improvement, you can have small improvements in everything and that helps. So, I think that really helped me to change the way I approach the whole quality thing. (TNE07: 170-3)
}

\begin{abstract}
A student in a low and middle income country had found that some of the modules were largely theoretical. She was in no position to apply the appraisal systems she was taught in health economics, and she had found evidence-based medicine too abstract, understanding some parts and not others. She put this down to the fact that she didn't make evidence-based decisions in her job:
\end{abstract}


I didn't truly grasp it, I thought I grasped a little bit of it, but not really, not very much. (TNE15:294-5)

One student with experience in a low and middle income country had anticipated that the module on emergency response would be useful. The student said:

\begin{abstract}
In developing countries, poor people are more exposed to emergencies, to disasters actually, so I thought that because there's quite a diverse group of students in this programme, they might be interested to take this important course as public health professionals. (TNE12:160-4)
\end{abstract}

\begin{abstract}
However, she found that the examples were very UK-based, and was disappointed with this, feeling that the systems in place to respond to emergencies were not easily transferable to a low-income country.
\end{abstract}

A student commented that the MPH encouraged students to apply what they were learning to their situation, but that it was not always easy to live up to the ideals set by the course content. For example, she had learnt that:

\begin{abstract}
When you design a study, you need to have the data, you need to have things in place to, find information. (TNE09:219-20)
\end{abstract}

\begin{abstract}
Yet the reality for the student was that in their own country, even basic data collection was sparse.
\end{abstract}




\title{
Assessments
}

Overall, the students had positive experience of the assessment and assignment approaches used on the course:

\begin{abstract}
Most of them were, on the course were essay kind of, so ... yeah, it's what
\end{abstract} I kind of expected for an online course. (TNE15:305-6)

The assessments, the way they were structured was good in a way, because as a part time student of course I have to go to work ... The allocated time was always sufficient for me. (TNE03:219-221)

One student in a low and middle income country saw the assessments as particularly helpful for general learning and development.

\begin{abstract}
I really do appreciate that because they assessed almost everything, the writing styles, the content you know. And sometimes personally I didn't really have enough background. We are not used to that, we are not used to so much reading. It takes time ... it takes me a lot of effort to reach the standard they want ... but I do really, I like that. It's challenging, but it's helpful. (TNE05:240-50)
\end{abstract}

The assessment format was appreciated as well:

I like how we do it here, like you're given assignments, you relate to it, you use the course material. (TNE07:487-8) 
The scenarios really give you time to relate to the work, and so implement it you know. (TNE7: 503-4)

One student had had a bad experience with assignment marking. She began by noting that the grading structure was different in the UK, saying that in their country $60 \%$ is not that good, whereas in the UK it is not that bad:

I was used to getting A B's, and coming to the UK and getting a 60, I was devastated. (TNE12: 210-11)

\begin{abstract}
A student from a high-income country had experienced online exams in her undergraduate course, and thought that the University of Manchester could do the same:
\end{abstract}

A written exam as opposed to a paper every single time. Like you could do long answer questions, you know, and you get like a time limit ... It would all be either multiple choice or long answer, and yes of course you run the risk of having students work together on it but it's still achieving the fact that they're going over the content. (TNE12:639-646)

However, access to resources was felt to restrict one student's ability to write a good assignment: 
Some assessments actually require assistance one-to-one, or face-to-face instruction. Especially assessments that involve calculation or interpretation of some theoretical approach. TNE03:231-4)

She argued that in her very small country there were no big libraries and only one university, and:

It's difficult to find somebody to assist you with small matters. (241-2)

Following on concerns that the content was overly UK-based, there was a suggestion that in designing the assessments, tutors needed to consider how far away some people are and think about providing options when it comes to asking questions:

\begin{abstract}
I know you're supposed to be international, but sometimes you're very, very far away from what actually takes place on the ground. So sometimes, if they like give a question that had two options, then somehow you'd be a little bit more comfortable. (TNE15:270-73)
\end{abstract}

One student noted that there was a certain level of complaint from other students about the assessments, but said that people knew when they began the course what it would be like:

\footnotetext{
Well, the thing is they've chosen to study. They know they're doing a course with people from other areas, within the course, so they can't say it's
} 
a disadvantage if they chose it. I mean they chose it, so to say that they're disadvantaged, they knew what they were getting themselves into.

(TNE08:329-333)

\section{Using technology}

Even though the study aimed to move beyond the experience of the technology per se, its discussion was not specifically prevented by the researcher. Several important challenges of online distance learning were reported relating to technology. A student in a low-income country did not have a stable Internet connection because of an intermittent power supply:

With the power cuts, the power is usually unreliable. Actually, at the time when I was doing my end-of-semester exam we had a power cut for I think four days. So, there are challenges, although we are told that you have to push beyond them. (TNE09:311-4)

Another student in a developing country had problems with the university virtual private network (VPN). This makes it easier but does not preclude access to the university online library amongst other things. She said the IT Services Team at the university tried to help, but couldn't:

I don't know why, if it's because of my computer or it's because of no knowledge of IT. (TNE05:135-6).

She could find only very limited local help with information technology: 
They can't help me, so I'm just like, you know I have to go through Google, I can't really navigate through the Library at all. That's the weakness I have here. (TNE05:144-5)

Registering and then signing on to the VPN removes the need for the student to enter their username and password every time they want to access an online journal article/e-book. Therefore, it provides a more seamless route to online resources, with students having to log on only once, during each online session, rather than for each online journal article they wish to open and read.

\section{Discussion}

The aim of the current research was to provide a better insight into the learning needs of students whose domicile country was outside of the European Union (i.e., non-nationals with regards to the UK) and who were registered on an online MPH programme. The results contributed to an existing scant and fragmented literature base on the learning needs of students whose domicile country is outside the EU; thus, they are non-nationals in relation to the UK. The experiences reported by students in this study are unlikely to be unique as a whole to ODL, but they highlighted aspects that may require different pedagogical and design approaches in the online environment.

The interviews reaffirmed the need to design and deliver programmes that recognised what students perceived to be important aspects relating to their 
current context, drawing attention to what Maringe and Woodfield, (2013) discuss with regards to learning spaces for international teaching.

Ensuring that academics are able to contextualise students' environments is likely to be more challenging for ODL, in particular, when students are in different countries (Rasi et al., 2014). In fact, it is reasonable to assume that academics will encounter students for whom they have little, if any knowledge of the student's domicile country, including its culture, infrastructure and economy - along with other key factors likely to bridge learning and its application from the taught curriculum, to individual students' lives. One approach to facilitate this is to create opportunities within the programme delivery, such as discussion forums and tutorials, where the emphasis is on giving academics a chance to better frame the curriculum so that it becomes more specific to their students' needs.

At the same time, from a quality perspective, it is inadequate to make assumptions about academics' sensitivities and deeper interpretation of different cultural contexts, philosophical beliefs and pedagogical expectations (Bentley, Tinney, \& Chia, 2005; Quality Assurance Agency, 2014). In the current study, there was evidence that some students did not think tutors appreciated their own personal and professional circumstances. Certainly delivering online learning to international students is regarded as a challenging activity (O’Mahony, 2014) perhaps in part because of potentially fewer opportunities for formal and informal communication between tutors and students. Those that do occur could be enhanced by ensuring that all tutors have a deeper understanding of their students' worlds in their entirety (Daniels, 2013) and use it to inform the nature of the formal and informal curriculum. When done properly, tutors and students 
develop a more reciprocal cultural exchange (Bovill, Jordan, \& Watters, 2014) where mutual understanding can support a more sustained transformative development in terms of internationalisation (Mott-Smith, 2013: Sadykova, 2014).

Despite students registering for an online programme of study, one cannot therefore assume that all students will have adequate technical skills, nor that they are prepared to interact, either synchronously or asynchronously, with their online classmates. The current study recognised that some international students were reluctant to participate in the online discussion boards/forums, often used by the tutors to encourage mutual exchange of experiences on particular topics and for assessing discrete aspects of the course. Similar findings have been reported in other international programmes (Collinson \& Halliwell, 2014), and the reasons for this remain unclear, although there has been a tendency to focus on cultural factors.

A common approach to investigate the association of online communication and culture is the framework put forward by Hofstede (1984), which includes a method for categorising the degree of interdependence a society maintains among individuals (Hofstede, 1984). More recent research has identified the likelihood of many issues that interact and impact on individual and groups of students' online learning experience. These include student satisfaction with the programme (Aparicio, Bacao, \& Oliveira, 2016), the influence of different semiotics in the online environment (Bayne, 2008), students' attitudes and experience of different virtual learning environments (Boulton, 2014). 


\section{Conclusions}

The results from the study presented in this paper make an important contribution to the relatively scant research base on the learning experiences of international ODL students. The study draws attention to the importance of opportunities in the programme design for academics to make links between the formal curriculum and students' local environment. Different approaches need to be considered for ODL as it brings additional challenges to when teaching face-to-face. Academics' training and ensuring open dialogue with and between students regularly throughout an ODL are likely to facilitate a more open exchange of ideas and deepen both academics' and their students' understanding about the subject overall.

Notes on contributors

Dr Harrison has extensive experience running online distance learning programmes in higher education, specifically in health-related disciplines. He is actively involved with quality assurance, research and development across higher education, predominantly in the UK.

Ms Harrison lectures on the value and contribution of arts and creativity to population health.

Dr Robinson lectures on the topic of qualitative research methods in population health.

Dr Rawlings is a research consultant with expertise leading projects in health, welfare and social care in different countries.

\section{References}

Altbach, P. G., Reisberg, L., \& Rumbley, L. (2010). Trends in globl higher education: Tracking an academic revolution. Paris: UNESCO.

Aparicio, M., Bacao, F., \& Oliveira, T. (2016). Cultural impacts on e-learning systems' success. The Internet and Higher Education, 31, 58-70. Retrieved 
from https://www.sciencedirect.com/journal/the-internet-and-highereducation

Bates, A. (2015). Teaching in a digital age. Retrieved from https://opentextbc.ca/teachinginadigitalage/

Bayne, S. (2008). Higher education as a visual practice: Seeing through the virtual learning environment. Teaching in Higher Education, 13, 395-410. doi:10.1080/13562510802169665

Bentley, J., Tinney, M., \& Chia, B. (2005). Intercultural Internet-based learning: Know your audience and what it values. Educational Technology Research and Development, 53, 117-127. doi:10.1007/BF02504870

Boulton, H. (2014). Cross cultural comparison: The introduction of new technology with postgraduate students in Hong Kong and the United Kingdom. In K. Li \& K. Yuen (Eds.), Emerging modes and approaches in open and flexible education (pp. 103-117). Hong Kong: Open University of Hong Kong Press.

Bovill, C., Jordan, L., \& Watters, N. (2014). Transnational approaches to teaching and learning in higher education: Challenges and possible guiding principles. Teaching in Higher Education, 20, 12-23. doi:10.1080/13562517.2014.945162

Braun, V., \& Clarke, V. (2006). Using thematic analysis in psychology. Qualitative Research in Psychology, 3, 77-101. doi:10.1191/1478088706qp063oa

British Council. (2013). The shape of things to come. The evolution of transnational education: Data, definitions, opportunities and impacts analysis. London: Author.

Collinson, S., \& Halliwell, C. (2014). Understanding and promoting student engagement via online interactive tutorials: Development of an internationally relevant environmental chemistry and health context based learning activity. Milton Keynes: Higher Education Academy.

Daniels, J. (2013). Internationalisation, higher education and educators' perceptions of their practices. Teaching in Higher Education, 18, 236-248. doi:10.1080/13562517.2012.719158

Francis, J., Johnston, M., Robertson, C., Glidewell, L., Entwistle, V., Eccles, M., \& Grimshaw, J. (2010). What is an adequate sample size? Operationalising 
data saturation for theory-based interview studies. Psychological Health, 25, 1229-1245. doi:10.1080/08870440903194015

Glaser, B. (1992). Basics of grounded theory analysis. Mill Valley, CA: Sociology Press.

Goldhill, O. (2013, July 5). 4G coverage on Mount Everest. The Telegraph. Retrieved from http://www.telegraph.co.uk/technology/mobilephones/10161553/4G-coverage-on-Mount-Everest.html

Guest, G., MacQueen, K., \& Namey, E. (2012). Applied thematic analysis. Los Angeles, CA: Sage.

Hammersley, M. (2015). Sampling and thematic analysis: A response to Fugard and Potts. International Journal of Social Research Methodology, 18, 687688. doi:10.1080/13645579.2015.1005456

Hammersley, M., \& Atkinson, P. (2007). Ethnography: Principles in practice (2nd ed.). London: Routledge.

Hofstede, G. (1984). Cultural dimensions in management and planning. Asia Pacific Journal of Management, 1, 81-99. doi:10.1007/BF01733682

IELTS. (2018). What is IELTS? Retrieved from https://www.ielts.org

Internet Live Stats. (2016). Internet users. Retrieved from http://www.internetlivestats.com/internet-users/

Katsarova, I. (2015). Higher education in the EU: Approaches, issues and trends. Retrieved from http://www.europarl.europa.eu/thinktank/en/document.html?reference=EPR S_IDA(2015)554169

Knight, J. (2016). Transnational education remodeled: Toward a common TNE framework and definitions. Journal of Studies in International Education, 20, 34-47. doi:10.1177\%2F1028315315602927

Kosmützky, A., \& Putty, R. (2016). Transcending borders and traversing boundaries. Journal of Studies in International Education, 20, 8-33. doi:10.1177\%2F1028315315604719

LSE Students' Union. (2016). The attainment gap at LSE. London: Author. Retrieved from https://www.lsesu.com/pageassets/campaigning/studentreps/Attainment-Gap-at-LSE-v2.pdf 
Maringe, F., \& Woodfield, S. (2013). Contemporary issues on the internationalisation of higher education: Critical and comparative perspectives. Compare: A Journal of Comparative and International Education, 43, 1-8. doi:10.1080/03057925.2013.746545

Mechant, P. (2014). An illustrated framework for the analysis of Web2.0 interactivity. In C. Tsekeris \& I. Katerelos (Eds.), The social dynamics of Web 2.0: Interdisciplinary perspectives (1st ed., pp. 263-282). Oxon:

Routledge.

Mott-Smith, J. A. (2013). Viewing student behavior through the lenses of culture and globalization: Two narratives from a US college writing class.

Teaching in Higher Education, 18, 249-259. doi:10.1080/13562517.2012.72522

Nowell, L., Norris, J., White, D., \& Moules, N. (2017). Thematic analysis: Striving to meet the trustworthiness criteria. International Journal of Qualitative Methods, 16(1), 1-13. doi:10.1177\%2F1609406917733847

O’Mahony, J. (2014). Enhancing student learning and teacher development in transnational education. York: Higher Education Academy.

Quality Assurance Agency. (2014). Assuring quality for international students studying in the UK: A guide for UK higher education providers.

Gloucester: Author.

Rasi, P., Hautakangas, M., \& Väyrynen, S. (2014). Designing culturally inclusive affordance networks into the curriculum. Teaching in Higher Education, 20, 131-142. doi:10.1080/13562517.2014.957268

Sadykova, G. (2014). Mediating knowledge through peer-to-peer interaction in a multicultural online learning environment: A case study of international students in the US. International Review of Research in Open and Distance Learning, 15(3), 24-49. doi:10.19173/irrodl.v15i3.1629

Strauss, A., \& Corbin, J. (1998). Basics of qualitative research techniques and procedures for developing grounded theory (2nd ed.). London: Sage.

World Bank. (2017). County-level national income. Retrieved from https://data.worldbank.org/country 